D:\Nsurg\Vol. 23, No. 4, Oct. - Dec., 2019\Nsurg-14.Doc $\quad$ (A) $\quad$ P. $317-320 \quad$ II

CASE REPORT

\title{
Proximal Migration of Lumboperitoneal Shunt Catheter up to Cervical Spine
}

\author{
MUHAMMAD SOHAIL UMERANI' ${ }^{1}$, GABR AHMED MOSTAFA ${ }^{1}$ \\ AHMED ADEL ABDEL LATIF FARAG, ${ }^{2}$ ASAD ABBAS ${ }^{3}$ \\ Department of Neurosurgery, ${ }^{1}$ King Fahd Military Medical Complex, Dhahran KSA. \\ ${ }^{2}$ Armed Forces Hospital Southern Region, KSA. \\ ${ }^{3}$ University Hospitals Coventry and Warwickshire, UK \\ DOI: https://doi.org/10.36552/pjns.v23i4.353
}

\begin{abstract}
Lumboperitoneal (LP) shunt had been in use as an internal cerebrospinal fluid (CSF) diversion for a variety of different indications, namely benign intracranial hypertension, communicating hydrocephalus, slit ventricle syndrome and CSF fistulas.Generally, considered to be a simple surgical procedure, butcertain potential complications are associated with this technique, including chronic subdural hematoma, subarachnoid hemorrhage, acquired Chiari malformations and migration of the shunt tubing. ${ }^{1,2}$ Proximal intrathecal migration of LP shunt catheter tip, high up in the cervical spine is a rare reported complication. ${ }^{3-8}$ If doubtful on $X$-rays, Computed Topography (CT) scan confirms the diagnosis. Although, the multi factorial's proximal migration is usually because of a faulty technique when anchoring sutures are loosened or cut. The measures employed to avoid this potential complication include appropriate techniques for securing the LP shunt tube at the proximal lumbar and the distal peritoneal insertion sites with suture collars, thus enabling fixation of the tube. We report a case of an obese middle age female who developed proximal migration of the lumbar tube up to the cervical spine, after having undergone LP shunt for pseudotumor cerebri.
\end{abstract}

Keywords: Lumboperitoneal (LP) shunt, proximal migration, cervical spine.

\section{CASE REPORT}

This case report is of a 31 years old obese female who is known to have benign intracranial hypertension and had undergone LP shunt at the age of 29 years because of deterioration in her vision.Later, after about 15 months she presented tothe outpatient clinic with mild back pain of 4-5 months duration along with a soft swelling at the previous lower back operative site.The painless swelling was gradually increasing without any discharge and was not associated with headache or visual compromise. There was no history of fever or weight loss. She weighed $140 \mathrm{~kg}$. On examination, there was a non-tender, soft, cystic midline swelling at the previous operative site in the lumbar spine, which was non-reducible and non-pulsatile. There was no neurological deficit in lower limbs. Radiological assessment revealed that the proximal intra spinal tube of the LP shunt had migrated cephalad up to the level of $6^{\text {th }}$ cervical vertebra (Fig. 1). This was associated with coiling of the shunttubing externally into the lumbar cystic space, suggestive of the tube being pulled out of peritoneal cavity (Figures 2, 3).

After thorough counseling, she underwent surgical intervention with the assistance of a Laparoscopic Surgeon. Per operatively the midline cystic cavity was explored and the proximally migrating intrathecal tube was retrieved till the desired level under image intensifier and was meticulously anchored with the soft tissue. Acknowledging the difficulty due to her obesity, the distal end of the shunt tubing was placed intra peritoneal under laparoscopic guidance and secured with anchoring knots to prevent any further 
complication. Postoperatively she remained well and was later discharged in a stable condition.

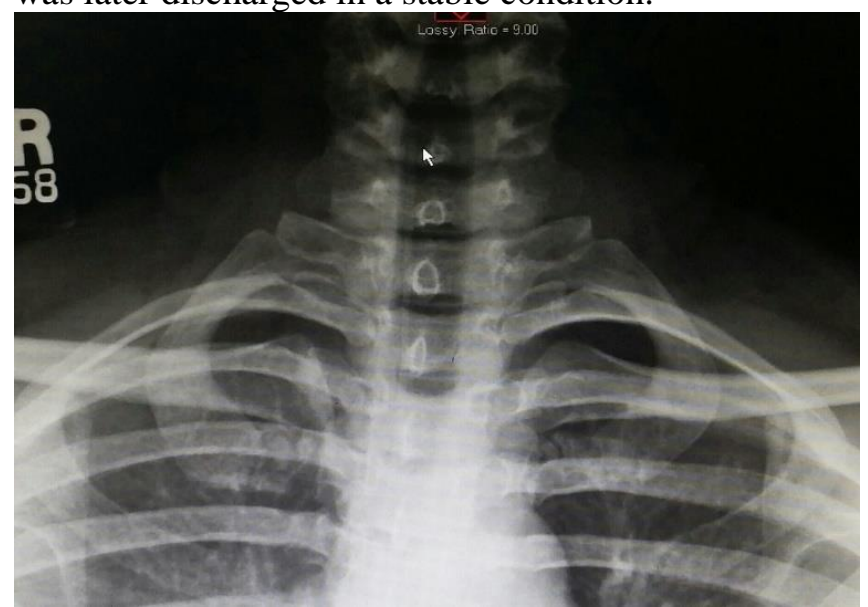

Fig. 1: $X$-ray cervicodorsal spine AP view showing tip of the proximally migrated $L P$ shunt reaching up to Cervical 6 vertebra.

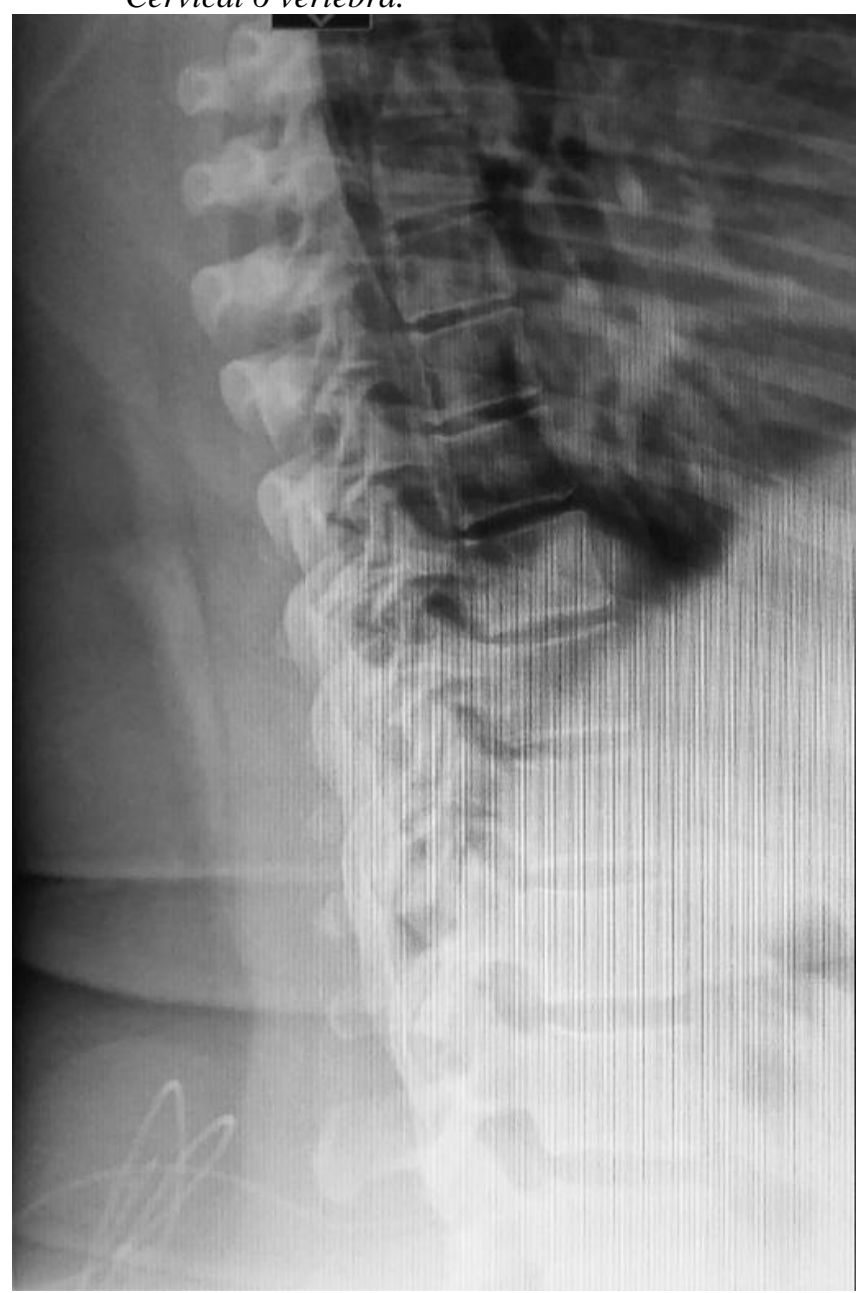

Fig. 2: X-ray dorsolumbar spine lateral view showing coiled shunt tube in posterior lumbar subcutaneous cystic space.

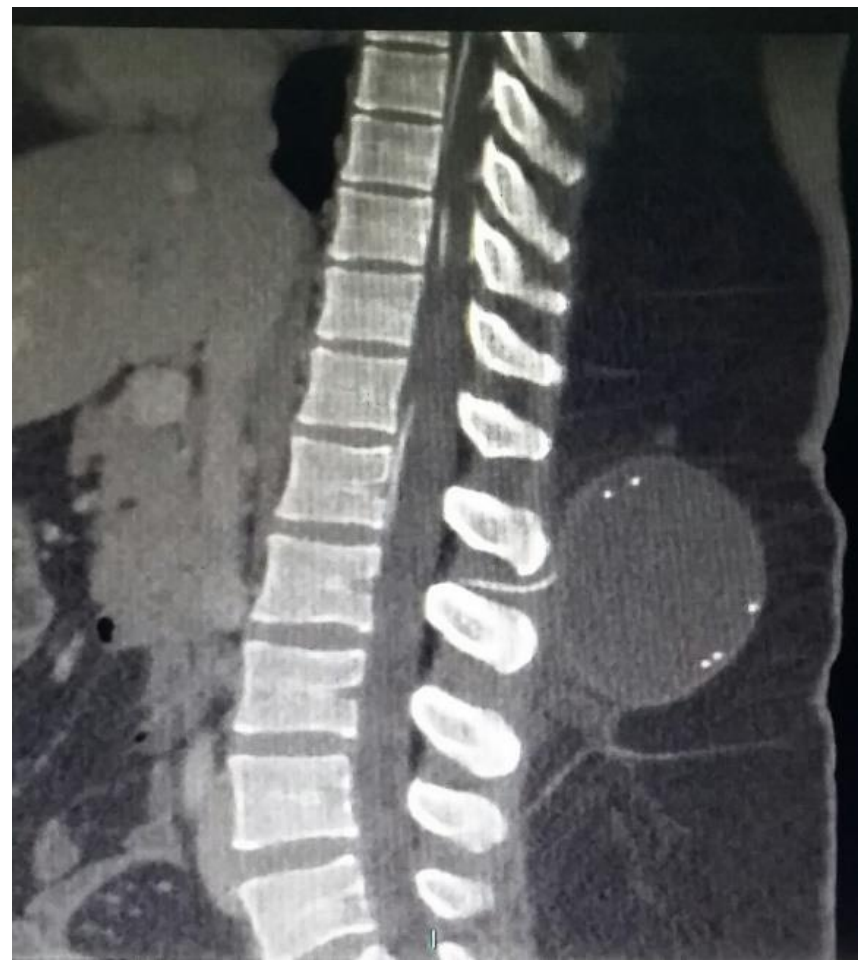

Fig. 3: Well circumscribed cystic lesion is seen in the subcutaneous tissues of the back, posterior to LI and L2 spinous processes measuring $6.4 \times 5.2 \times 7$ $\mathrm{cm}$ in anterio-posterior, transverse and craniocaudal respectively, with the shunt tube coiled within its cavity.

\section{DISCUSSION}

Internal CSF diversion procedures are generally considered safe in comparison to external diversion techniques. Some surgeons are more inclined towards LP shunts rather than a VP shunt because of its technical simplicity and minimal intracranial complications. ${ }^{9-10}$ LP shunts are generally used in communicating hydrocephalus, normal pressure hydrocephalus, benign intracranial hypertension and in managing natural or iatrogenic CSF leaks. ${ }^{11-13}$ Two types of LP shunts are generally used; one is a valve mediated and the other is valve less type.As with any surgical intervention, certain complications are associated with this procedure. These include shunt obstruction, fracture, infection, subarachnoid hemorrhage, chronic subdural hematoma, Acquired Chiari malformation, radiculopathy, myelopathy and migrations of the shunt tube. ${ }^{14,15}$

Migration of the tubing distally in the peritoneum has been reported in the literature,but rare is the cephalad migration up in the dorsal or cervical spinal 
subarachnoid space or even intra cranially., ${ }^{6,16-17}$ Partial or complete shunt displacement from the peritoneal cavity has been seen, with more cases being reported for the uni-shunt system, without a reservoir. Such an untoward complication may be due to the faulty anchoring technique of the shunt tubing. ${ }^{5,6}$ Appropriate focal physical examination would suggest the possibility of the shunt displacement out of the peritoneum.Simple X-rays at times are sufficient to reach the diagnosis with $\mathrm{CT}$ scan or MRI is reserved only if in doubt. Our patient presented with a midline swelling at the lumbar spine region, corresponding to the site of Tuohy needle insertion. Radiological evaluation confirmed it to be CSF collection with encircling of the tubing at this end.

The mechanism for proximal shunt migration is obscure and some possible explanations have been described. One possible explanation for this event could be obesity on top of factors that increase the intra-abdominal pressure like coughing, straining, etc. This occasional increase of abdominal pressure along with movements at the lumbar spine like, flexion, extension, lateral bending and axial rotation is sometimes enough to displace the tube out of the peritoneal cavity. ${ }^{5}$

Different modifications have been proposed by various authors in the literature. Some advocate the use of a LP shunt that incorporates a reservoir.Others have placed a connector between the peritoneal and the lumbar spinal tube. ${ }^{3}$ This can provide a more secure way in preventing displacement of peritoneal tube and eventual intra spinal shunt migration. Recently, programmable LP shunts have been used. ${ }^{18}$ These are not only effective in controlling excessive CSF drainage, but might also act as an anchor to prevent migration of the LP shunt. Nevertheless, prime importance should be given to the proper anchoring of the tubing to the fascia with suture collars usinga nonabsorbable suture. Thus the affixed tube on both sides of insertion ensures safety of spinal and peritoneal slippage of the shunt tubing.

\section{CONCLUSION}

Proximal migration of the LP shunt tubing is a rare and an avoidable complication. Such a condition should be suspected whenever the patient presents post operatively with a soft, cystic, midline lumbar swelling at the needle insertion site. Meticulous technique with anchored tubing to the fascia may warrant thesafety of this procedure.Modification of the tubing via. using a reservoir is of paramountsignificance, especially if the patient is obese.

\section{REFERENCES}

1. Suri A, Pandey P, Mehta VS. Subarachnoid hemorrhage and intra cerebral hematoma following lumboperitoneal shunt for pseudotumor cerebri: a rare complication. Neurol India. 2002; 50: 508-10.

2. Payner $\mathrm{TD}^{1}$, Prenger E, Berger TS, Crone KR. Acquired Chiari malformations: incidence, diagnosis, and management. Neurosurgery, 1994 Mar; 34 (3): 429-34.

3. Rodrigues D, Nannapaneni R, Behari S, Prasad M, Herwadkar A, Gerber CJ, Mitchell P. Proximal migration of a lumboperitoneal unishunt system. J Clin Neurosci. 2005; 12: 838-41.

4. Satow T, Motoyama Y, Yamazoe N, Isaka F, Higuchi K, Nabeshima S. Migration of a lumboperitoneal shunt catheter into the spinal canal-case report. Neurol Med Chir (Tokyo). 2001; 41: 97-9.

5. Yoshida S, Masunaga S, Hayase M, Oda Y. Migration of the shunt tube after lumboperitoneal shunt-two case reports. Neurol Med Chir (Tokyo). 2000; 40: 594-6.

6. Caroll TA, Jakubowski J. Intrathecal migration of a lumboperitoneal shunt. Br J Neurosurg. 2000; 14: 4967.

7. Alleyne $\mathrm{CH}$, Shutter LA, Colohan AR. Cranial migration of a lumboperitoneal shunt catheter. South Med J. 1996; 89 (6): 634-6.

8. Anthogalidis EI, Sure U, Hellwig D, Bertalanffy $\mathrm{H}$ : Intracranial dislocation of a lumbo-peritoneal shuntcatheter: case report and review of the literature. Clin Neurol Neurosurg, 1999; 101 (3): 203-6.

9. Kang S. Efficacy of lumbo-peritoneal versus ventriculo-peritoneal shunting for management of chronic hydrocephalus following aneurysmal subarachnoid haemorrhage. Acta Neurochir (Wien). 2000; 142: 45-9.

10. Aoki N. Lumboperitoneal shunt: clinical applications, complications, and comparison with ventriculoperitoneal shunt. Neurosurgery, 1990 Jun; 26 (6): 998-1003.

11. Burgett RA, Purvin VA, Kawasaki A. Lumboperitoneal shunting for pseudotumor cerebri. Neurology, 1997 Sep; 49 (3): 734-9.

12. Ide T, Aoki N, Miki Y. Slit ventricle syndrome successfully treated by a lumboperitoneal shunt. Neurol Res. 1995 Dec; 17 (6): 440-2.

13. Bret P, Hor F, Huppert J, Lapras C, Fischer G. Treatment of cerebrospinal fluid rhinorrhoea by percutaneous lumboperitoneal shunting: review of 15 cases. Neurosurgery, 1985; 16: 44-7.

14. Wang VY, Barbaro NM, Lawton MT, Pitts L, Kunwar S, Parsa AT, Gupta N, McDermott MW. Complications 
of lumboperitoneal shunts. Neurosurgery, 2007; 60: 1045-8.

15. Payner TD, Prenger E, Berger TS, Crone KR. Acquired Chiari malformations: incidence, diagnosis, and management. Neurosurgery, 1994: 34 (3): 429-434.

16. Bunc G, Vorsic M, Ravnik J, Velnar T. Proximal migration of a lumboperitoneal shunt into the prepontine and ambiens cisterns. Clin Neurol Neurosurg. 2011; 113 (1): 75-7.
17. Solaroglu I, Okutan O, Beskonakli E. Foraminal migration of a lumboperitoneal shunt catheter tip. J Clin Neurosci. 2005; 12: 956-8.

18. Toma AK, Dherijha M, Kitchen ND, Watkins LD. Use of lumboperitoneal shunts with the Strata NSC valve: a single-center experience. J Neurosurg. 2010; 113: 13048.

\section{Additional Information}

Disclosures: Authors report no conflict of interest.

Ethical Review Board Approval: The study was conformed to the ethical review board requirements.

Human Subjects: Consent was obtained by all patients/participants in this study.

Conflicts of Interest:

In compliance with the ICMJE uniform disclosure form, all authors declare the following:

Financial Relationships: All authors have declared that they have no financial relationships at present or within the previous three years with any organizations that might have an interest in the submitted work.

Other Relationships: All authors have declared that there are no other relationships or activities that could appear to have influenced the submitted work.

Address for Correspondance Dr. Asad Abbas, Deprtment of Neurosurgery University Hospitals Coventry and Warwickshire, UK Email:asad.abbas@live.com

\begin{tabular}{|l|l|l|l|}
\hline \multicolumn{3}{|c|}{ AUTHORSHIP AND CONTRIBUTION DECLARATION } \\
\hline Sr.\# & Author's Full Name & Intellectual/Contribution to Paper in Terms of: & \\
\hline 1. & $\begin{array}{l}\text { Muhammad Sohail } \\
\text { Umerani } \\
\text { (Main/Principal Author). }\end{array}$ & 1. Proposed topic and Basic Study Design & $\begin{array}{l}\text { Signature by the } \\
\text { author(s) }\end{array}$ \\
\cline { 1 - 2 } 2. & $\begin{array}{l}\text { Gabr Ahmed Mostafa } \\
\text { (2nd Author) }\end{array}$ & 2. Data collection and calculations \\
\hline 3. & $\begin{array}{l}\text { Ahmed Adel Abdel Latif } \\
\text { Farag } \\
\text { (3rd Author) }\end{array}$ & 3. Analysis of data and interpretation of results etc. & \\
\hline 4. & $\begin{array}{l}\text { Asad Abbas } \\
\text { (4th Author) }\end{array}$ & 4. Literature review and manuscript writing \\
\hline
\end{tabular}

Date of Submission: 01-09-2019

Date of Revision: 20-12-2019

Date of Online Publishing: 25-12-2019

Date of Print: 31-12-2019 